\title{
Fpga Based Random Pulse Width Modulation for Three Phase VSI
}

\author{
Sreeja P, L.Padmasuresh, P.Muthukumar
}

\begin{abstract}
One of the inexpensive notions in present day power electronics control equipment is the objective of random pulse width modulation (RPWM) for control of semiconductor based power converters, accelerated by the progressively increasing anxiety with or regulations regarding electromagnetic fields, vibrations produced due to magnetic field and the induction of acoustic noise. The disperse or spread of acoustic noise spectra is obtained on induction motor by a differentcosimulation of RPWM generation for three phase inverter drive. This pattern is randomized by selecting the triangle randomly among the two triangles. The 8-bit linear shift register is used as feedback for arbitration selection. To generate the pulses sine reference wave is compared with east bit of the register output decide the winning triangle. The outcomes of cosimulation are presented for both RPWM and SPWM and compared Fundamental, Harmonic Spread Factor, Total Harmonic Distortion for various modulation index. Furthermore, Xilinx XC3S500E FPGA processor synthesis results are provided. The experimental validation of SPWM and RPWM are presented at the end and compared.
\end{abstract}

Index Terms: Random pulse width modulation, Total harmonic distortion, Field programmable gate array, Harmonic spread factor.

\section{INTRODUCTION}

In current few centuries, pulse width modulation (PWM) have been extensively paid more attentions in industrial variable drives applications [1]. The inverter configurations are attracted for induction motor drives. This drive generates unfavorable mechanical vibrations and acoustic switching noise due to passivity frequency PWM switching of the inverters. Random PWM [2]- [6] scheme has paying attention the solution to solve this issues in last three decades. The output harmonics spectra are distributed and scattered for implementing random PWM in an inverter. This is an important feature in an inverter and it causes the motor generated mechanical vibration and acoustic noise are reduced significantly. In general, the random PWM have been arranged into three classes:

1) Randomized carrier frequency PWM scheme; 2) randomized switching scheme; and 3) randomized pulse position PWM scheme.

This paper deals that the generation of random carrier pulses along with traditional sinusoidal pulse width

modulation scheme in digital application. MATLAB and

Revised Manuscript Received on July 22, 2019.

Sreeja $\mathbf{P}$, Department of EEE, Noorul Islam center for higher education, Thucklay, Tamilnadu, India. Engineering, Sasthamkotta, Kerala, India.

Dr.P.Muthukumar, Department of EEE, PVP Siddhartha Institute of Technology, Vijayawada, Andhra Pradesh, India.
Dr.L.Padmasuresh, Department of EEE, Baselios Mathew II College of

modelsim6.3f are used to generate random pulses of the proposed scheme owing to co-simulation feature.

In this paper includes of seven divisions. Section 2 explains that the various PWM schemes and Section 3 describes SPWM techniques and its digital implementation. The digital implementation of proposed method is explained in Section 4. Theoretical explanations are simulated and performance indices explained in Section 5. The proposed scheme simulation results and comparisons with conventional scheme are presented in Section 6. The conclusion of this paper given in section 7 .

\section{PULSE WIDTH MODULATION}

The development of power semiconductor technologies and digital processors, high speed switches are used power converters configurations to obtain variable speed, higher efficiency and supply required power parameters for induction motor applications. The pulse width modulation is implemented widely to generate the gate signals for power converter switches. PWM signals are pulse trains with variable pulse width and fixed frequency. There is one pulse of fixed magnitude in every PWM period. However, the duration(width) of the pulses changes from pulse to pulse according to a modulating reference signal. When a PWM signal is applied to the gate or base of a power transistor, it cause the "ON" and "OFF" intervals of the transistor to change from one PWM period to another PWM period according to the same modulating reference signal. The frequency of a PWM signal must be much higher than that of the modulating reference signal, the fundamental frequency, such that the available energy delivered to the motor and its load depends mostly on the modulating signal.

The advantages of PWM based switching power converter are

$\checkmark$ Temperature variation will not be digital circuits

$\checkmark$ Compatible with modern digital controllers (VLSI/FPGA[7][8] and advanced processors)

$\checkmark$ Easy to implement and control

In general, PWM techniques are classified :

1. SPWM

2. Single Pulse Width Modulation

3. Multi Pulse Width Modulation

Due to the development of progressive growth of technology, the other populated modulation techniques is also presented in various research papers: 1 . SVPWM [3] 2. RPWM[4][6].

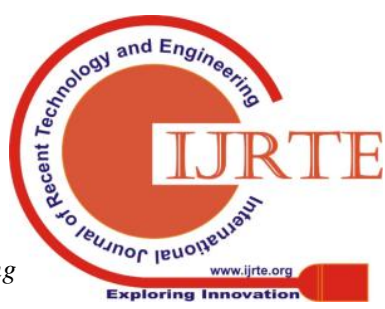




\section{A. Principle and Operation of Sinusoidal Pulse Width Modulation For Three Phase Inverter}

Amidst entire PWM methods, SPWM is one among the foremost widespread and easy strategies used in power electronics converter and to control electrical drives. Its main options will be briefed as sine-triangle wave comparison. A sinusoidal waveform (reference signal or wave) is compared with a triangle wave (carrier signal or wave with high frequency) and PWM signal output is obtained high state or high level (' 1 ') at sinusoidal wave is greater than the instantaneously varying triangular signal. Then the signal is low level ('0'). The switch is generated at each condition the sinusoidal wave originate across with triangular carrier wave [4] - [6]. therefore, the various come across points lead to variable duty cycle of the output wave shape.
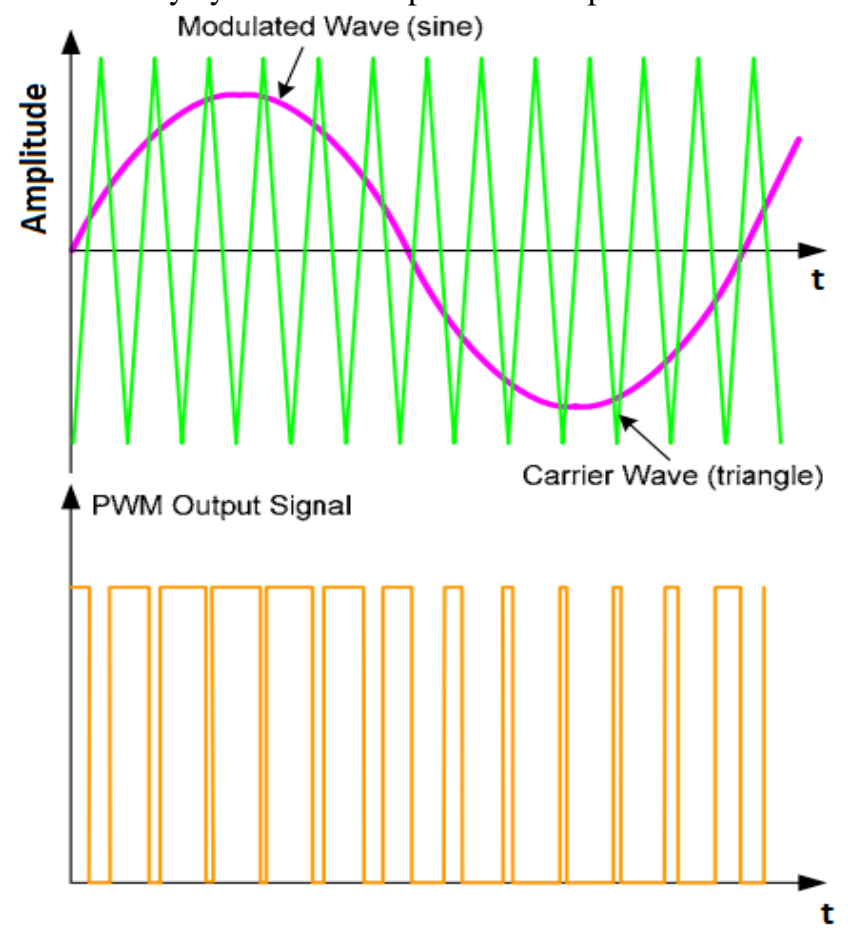

Fig 1. SPWM waveform generation

\section{DIGITAL IMPLEMENTATION OF SINUSOIDAL PULSE WIDTH MODULATION GENERATION}

In terms of the basic principle of SPWM illustrated in Fig 1, it's easy to implement using analog circuit (Fig 2). SPWM output digital signals are generated by in particular designed structure of signal comparator circuits along with the input of Sinusoidal or Sine reference and triangle carrier waves respectively.

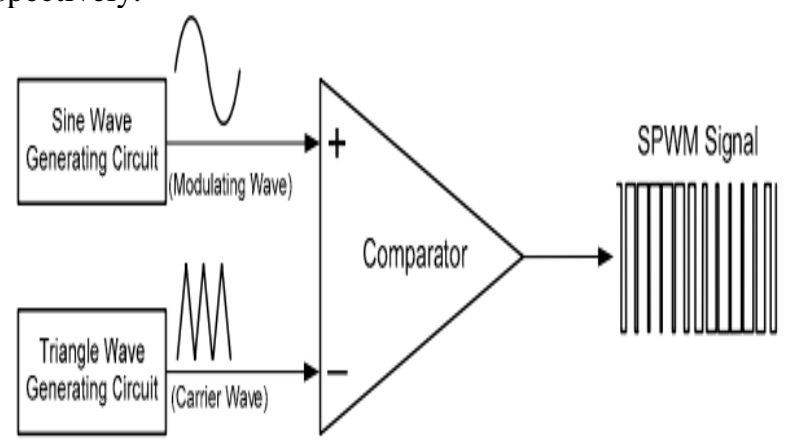

Fig2. Analog scheme for SPWM generation
But the control precision and reliability of this scheme are always not so satisfying due to the complicated analog circuit structure as well as the instability of the parameters of all analog devices.With the development of the digital VLSI, nowadays the software implementation for SPWM is completely adopted to realize high accuracy control. In Fig 3.shows a typical hardware of the SPWM generation circuit through the digital logic circuits combination.In the digital implementation of SPWM generation comprises of 3 major section. 1.Sinusoidal reference generation, 2. Triangle carrier generation section, 3.Comparison and Dead time insertion. In each of the above module comprises of derived clock generation module from the Master board clock.

\section{A. REFERENCE SINE WAVE GENERATION}

In the $50 \mathrm{~Hz}$ Sine Reference generation module only one quarter (0 to 90o) sine sample values has been used to generate the four quadrant which will generate the bipolar reference wave. 50 sine samples has been used in one quarter cycle,

So each sampling rate is $90 \mathrm{o} / 50=1.8^{\circ}$. shown in Fig 4 .

This sine samples multiplied with chosen modulation index, then will get the reference sine wave.

Sampling period calculation

200 sampling period $=20$ milliseconds for $50 \mathrm{~Hz}$.

1 sample period $=20$ milliseconds $/ 200=100 \mu$ seconds.

So that, $10 \mathrm{kHz}$ sampling frequency has been used to sample the data.

\section{B. 10 KHZ CLOCK GENERATION}

In the FPGA design, synchronous reset and $50 \mathrm{MHz}$ board clock has been used. Fig.5. shows the flowchart to generate the $10 \mathrm{kHz}$ clock. This clock has been used to sample sine data from look up table.

\section{TRIANGLE CARRIER WAVE GENERATION}

In Fig 3. shows the triangle carrier wave generation. Up down Counter based VHDL program has been used for carrier wave generation. In SPWM signals, Carrier signal frequency is equivalent to the switching frequency of power converter switches. $3 \mathrm{kHz}$ switching frequency has been selected for this case. Modulation index means it is the ratio of amplitude of the modulating wave to the amplitude of the Triangle wave. Positive peak of carrier wave is $\mathrm{Vc}=\mathrm{Vm}$ in positive half cycle and $\mathrm{Vc}=-\mathrm{Vm}$ for negative peak value.

\section{COMPARISON AND DEAD TIME INSERTION}

Three comparator and three not gates has been used to generate the 6 pulses. As per SPWM approach, if modulating signal higher the triangle signal, then the pulse will be high otherwise low. In each leg of converter lower and upper power semiconductor devices of have-not be turned on concurrently to avoid short circuit fault and EMI noise. 


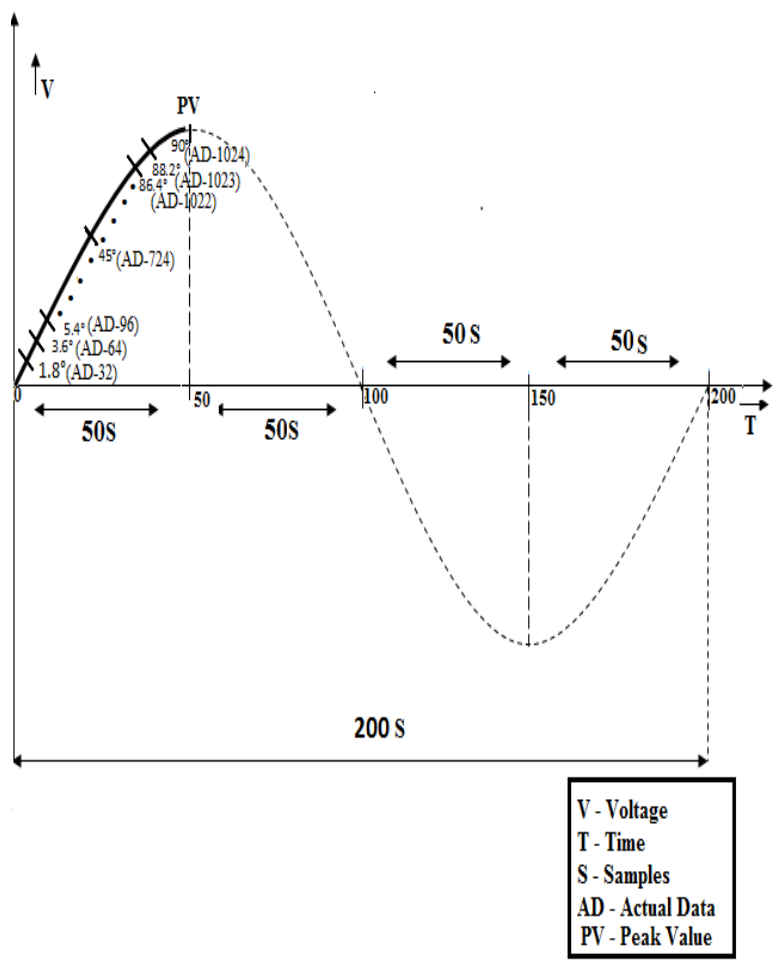

Fig 3. Typical Sinusoidal pulse width modulation generator using digital logic circuits

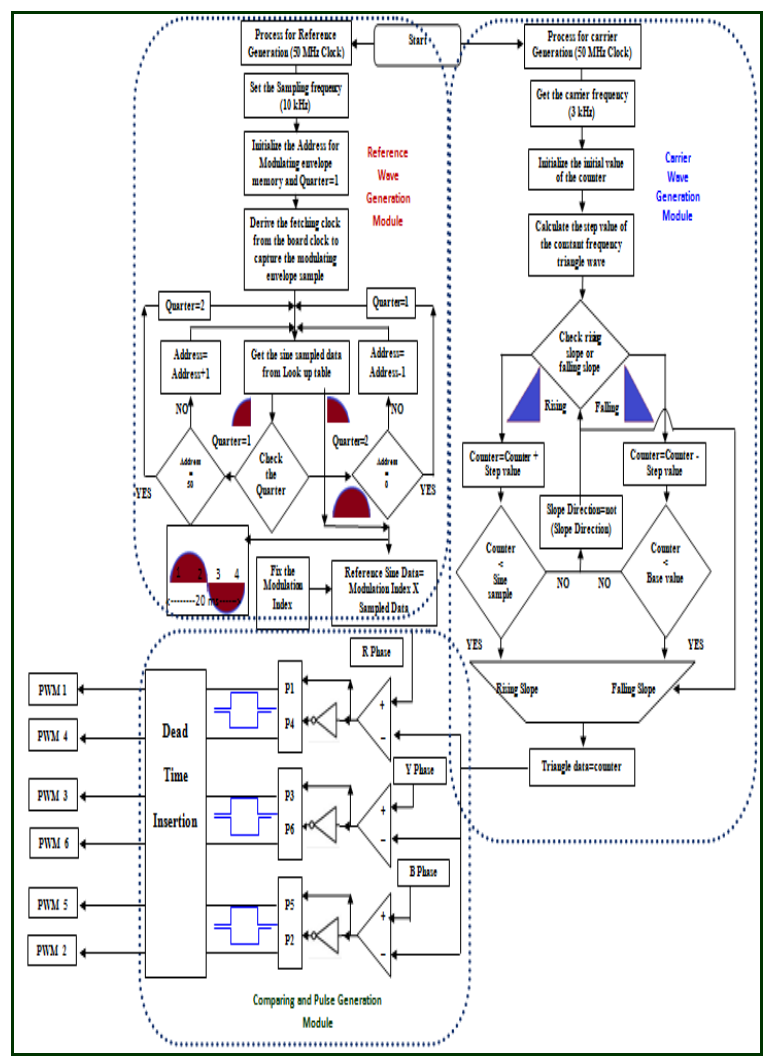

Fig 4. Sampling of sine reference

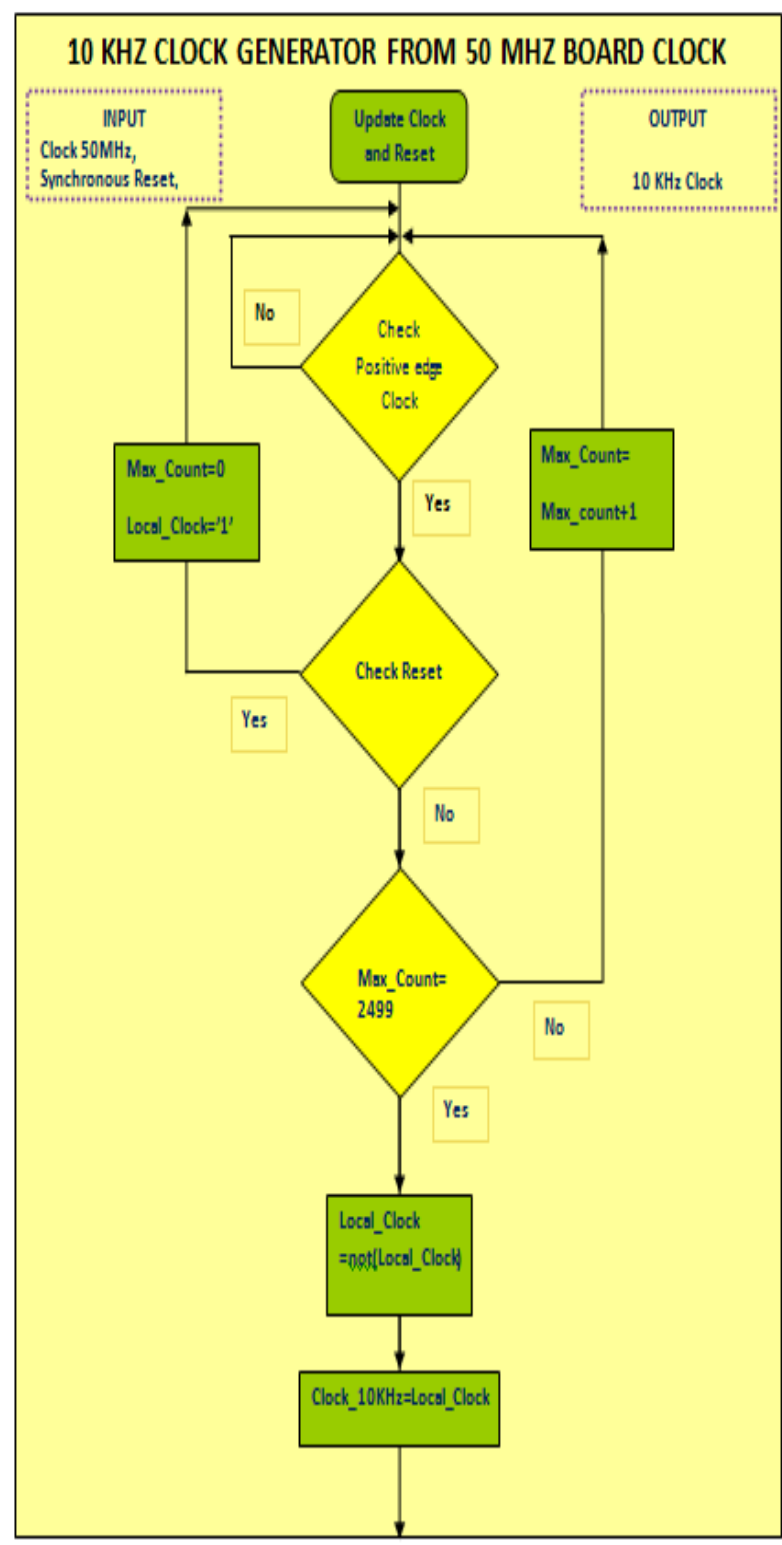

Fig 5 10kHz Clock Generation

Finally, this damage the snubber circuits and destroy power converter semiconductor devices. The shoot through problem due to electromagnetic interference (EMI) noise miscasting on is a major problem to the inverter's consistency. In order to avoid the shoot through fault, the dead time is inserted in between the turn-on and turn-off signals of same leg lower and upper semiconductor devices in the inverter. Here, 2.5 micro seconds has been used as a dead time.

\section{RANDOM PULSE WIDTH MODULATION}

A random carrier signal is attained as a result of randomly comprising two triangular carrier signals, each triangular carrier signals are same fixed or constant frequency, but each signals are opposite to each other by phase. The two carrier signals are randomly selected based on the states of the random binary sequence (RBS) which are "high" or "low") and its given in below table 1 . 
Table 1.Multiplexer Truth table

\begin{tabular}{|l|l|}
\hline RBS Status & Mutiplexer Output \\
\hline "0" & "C" \\
\hline "1" & "C bar" \\
\hline
\end{tabular}

The generation of random bit procedure is given in Fig 6. Two carrier signals are generated as fixed or constant frequency and provide as an input of multiplexer (2:1). Selection bit of multiplexer is based on the 8 bit LFSR. In each switching cycle, the shift register output has been reformed based on the input. Fig 7 shows that the comparator circuit diagram of RPWM generation and the switching frequency is considered as $3 \mathrm{kHz}$.

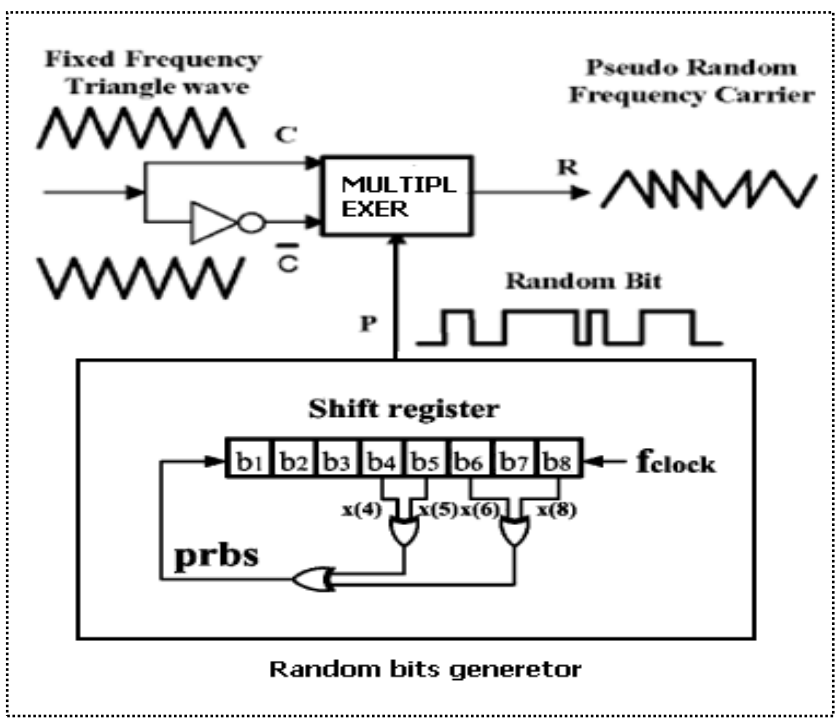

Fig 6. Random bit generation

In addition to the SPWM generation, random bit generation and inverted triangle generation are added for the digital implementation of the RPWM shown in Fig 8. The initial value of the triangle carrier is zero and the initial value of the inverted triangle carrier is the peak of the triangle. This is the only difference between the two triangles. Three xor gates and linear feedback shift register has been used to generate the random bit. . The interpretation selection of the two triangles is based on the output of the xor gate output which is normally call it as a pseudo random binary sequence(PRBS) bit.

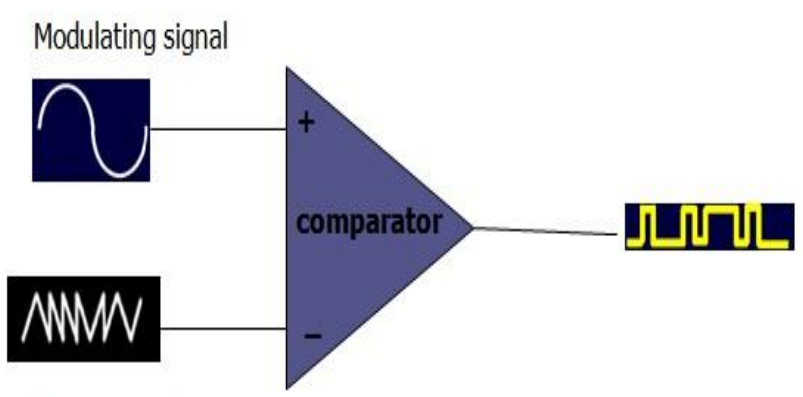

Carrier signal

\section{SIMULATION ENVIRONMENT}

In the technically designed cosimulation is time capable technique to describe mixed simulation. To develop this proposed work synthesizer and two simulators have been applied. The digital circuit design simulation was obtained from ModelsimSE 6. The modelling three power inverter is developed in Matlab / Simulink tool and analysis made through Powergui -FFT along with interface tools [7]. Modelsim-VHDL-design is integrated with RTL based test bench and functionality verification is also done. In all VHDL design modules the system clock has been used as an $50 \mathrm{MHz}$. The system design deactivation is obtained by active high reset. The stock up of data between two simulators is done workspace area. Fig.9 shows that the interfacing of design and analysis environments was done by HDL Co-simulation tool. The probability of the experimental execution is examined by tools of project navigator in Xilinx incorporated synthesis behavior analysis.

The assessment chart obtained from voltage harmonic spectrum has been specified for a number of modulation index $\left(\mathrm{m}_{\mathrm{a}}\right)$ ranges from 0.2 to 1.0 shown in table 3 . Generally, the ratio between peaks of modulating wave and carrier wave is the Modulation index. At modulation index $\mathrm{m}_{\mathrm{a}}=0.8$, the dominating harmonic order (D-H-O) voltage harmonic spectrum evaluation chart has been presented in table 4 . The diagram evidently represents that dominating harmonic peak amplitude is very a lesser amount as compared with the traditional techniques. The acoustic noise of PWM controlled induction drives performance is determined by the term of Harmonic spread factor (HSF) [4][6][7][8]. The concept of statistical deviation is employed for HSF calculation for evaluating the harmonic spread effect of the random PWM. The term of HSF is given below

$$
\begin{aligned}
& H S F=\sqrt{\frac{1}{N-1} \sum_{j>1}^{W}\left(H_{j}-H_{0}\right)^{2}} \\
& H_{0}=\sum_{j>1}^{W}\left(H_{j}\right) /(N-1)
\end{aligned}
$$

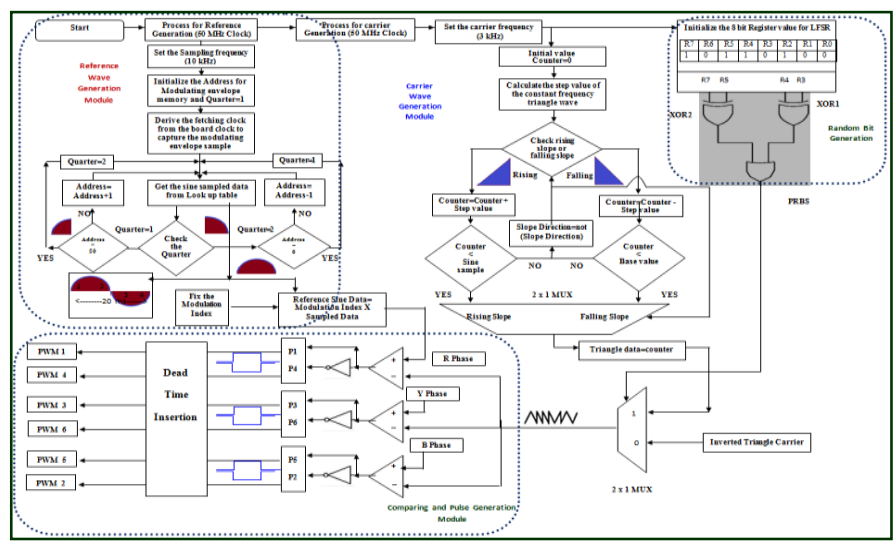

Fig 7. RPWM Generation

Published By:

Blue Eyes Intelligence Engineering \& Sciences Publication 
Fig10. Sinusoidal Reference Generation using Modelsim 6.3f

Fig 9. Typical random pulse width modulation generator

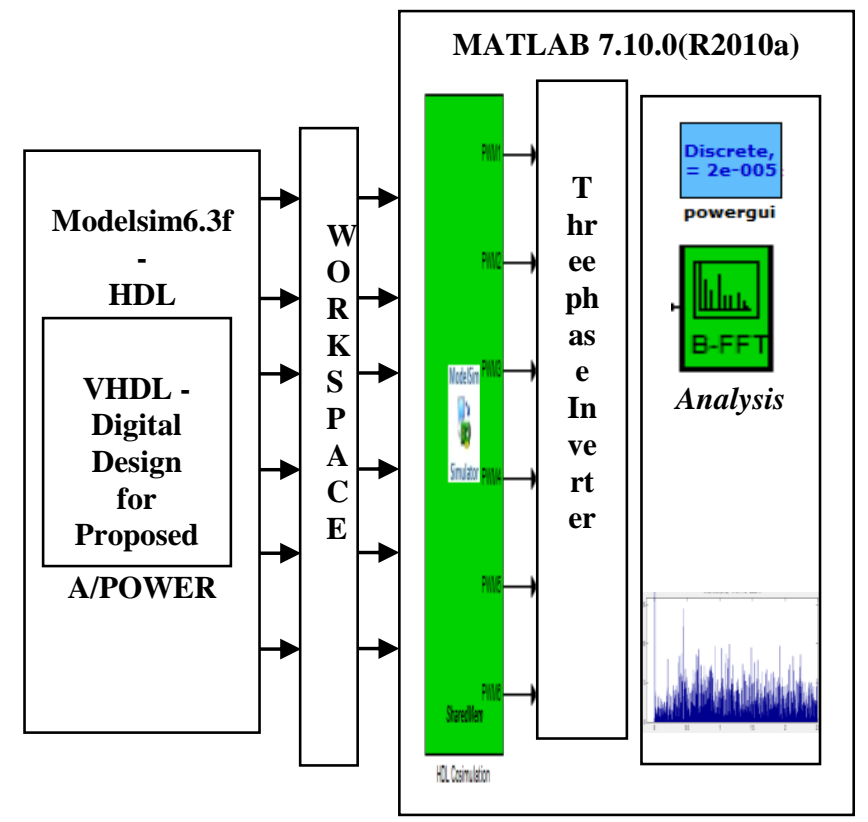

Where, ' $\mathrm{Hj}$ ' is jth harmonics amplitude, ' $\mathrm{H}_{0}$ ' is all ' $\mathrm{N}-1$ ' harmonics average value. The HSF should as low as possible and it enumerates effect of harmonic spectra spread by using random PWM method. The HSF is zero when an ideally flat spectrum of white noise (Young-cheol Lim et al 2010). The most essential performance indices (HSF, THD and Fundamental voltage) are attained by using Matlab FFT signal analysis. The THD is calculated from the ratio between distorted current/voltage to fundamental and it is calculated by

$$
\% \quad T H D=\sqrt{\frac{V_{2(r m s)}^{2}+V_{3(r m s)}^{2}+\ldots+V_{n(r m s)}^{2}}{V^{2}}}
$$

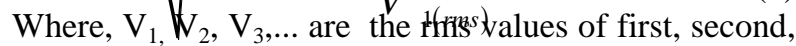
third,... harmonics.

\section{DISCUSSION ON SIMULATION AND EXPERIMENTAL RESULTS}

Fig.10 and Fig.11 shows the Sine reference wave generation output $(\mathrm{fm}=50 \mathrm{~Hz})$ and random Carrier generation output $(\mathrm{Fs}=3 \mathrm{kHz})$. In Fig 12. depicts the all the switching pulses generation with corresponding carrier and reference wave.

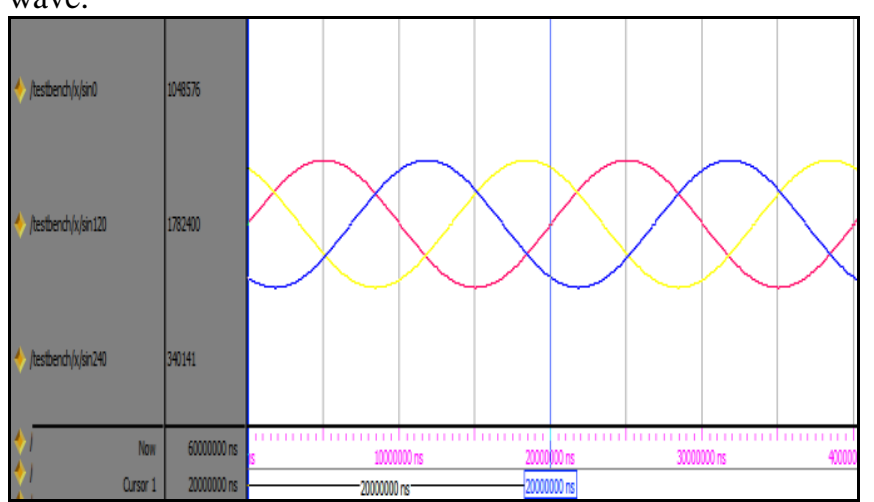

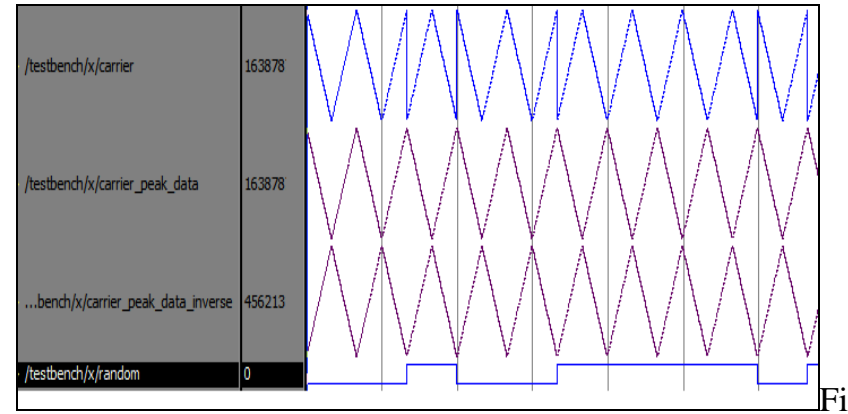

g. 11. Carrier Generation with Random bit using Modelsim $6.3 \mathrm{f}$

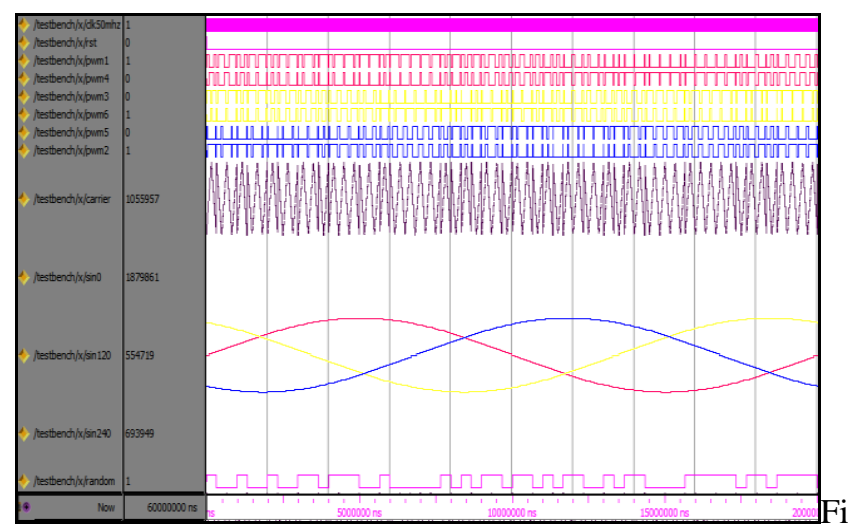

g. 12. Pulse Generation of RPWM with Random bit using Modelsim 6.3f

Random bit also generated every $3 \mathrm{kHz}$, which is also shown in Fig. 11 and Fig. 12.

$\checkmark$ In the performance comparison shown in table 2 , some of the points can be arrived.

$\checkmark$ In the Fundamental voltage point of view there is no much degradation in the RPWM compare with counterpart SPWM.

$\checkmark$ Fig 13 to Fig 15 are shown that the traditional SPWM, the multiplies and from $3 \mathrm{kHz}$ frequency the cluster of harmonic peak are existed. At the same moment, the cluster of harmonics are significantlycondensed at the switching frequency and its odd multiples of 3 by employment of random triangle PWM as shown in the Fig 7.

$\checkmark$ Harmonic spread factor is the acoustic noise performance predictor shows the clear dominations of the RPWM. The value of HSF is less though out the $\mathrm{m}_{\mathrm{a}}$ ranges from 0.2 to 1.0 where are its range is high and large variation in the SPWM.

$\checkmark$ It is observed that this RPWM will be useful for high speed application where the acoustic noise is major impact. 
$\checkmark$ The main feature of this proposed RPWM technique in digital implementation is employed with $13 \%$ of look up tables. The reference and carrier waves are developed by using 2 DSP based $18 \times 18$ multipliers. The sequential digital circuit design was developed by $50 \mathrm{MHz}$ board clock.

The proposed scheme has been validated with the designed system containing of an inverter structure with FPGA. The experimental setup has a autotransformer unit, inverter,

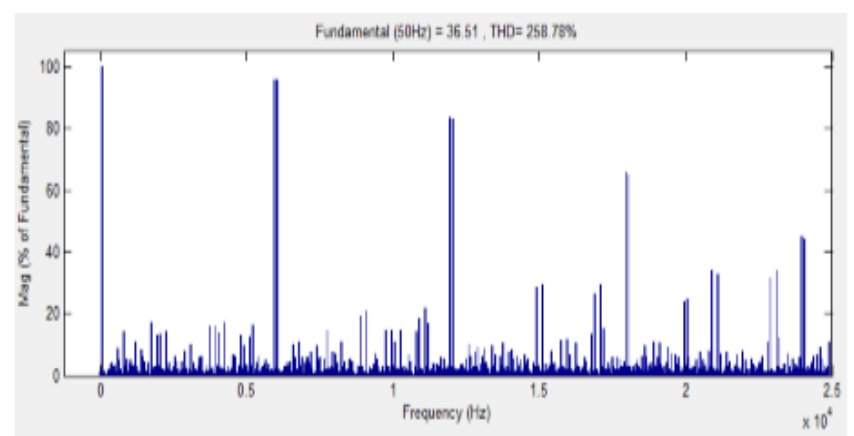

Modulation Index $\mathrm{m}_{2}=0.2$
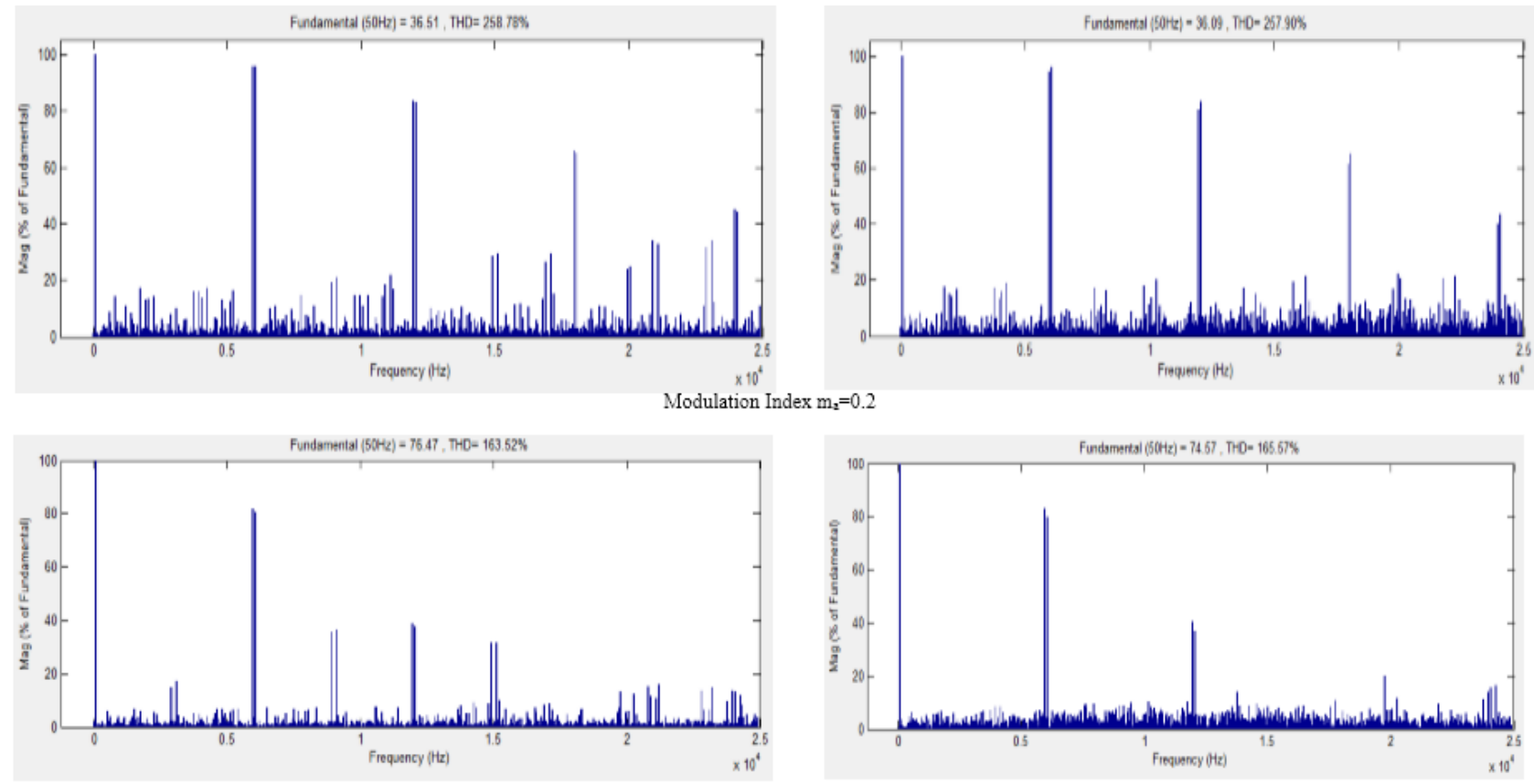

SPWM
FPGA board and an induction motor as a load.The inverter output was measured by using Digital Storage Oscilloscope (Yokogawa).

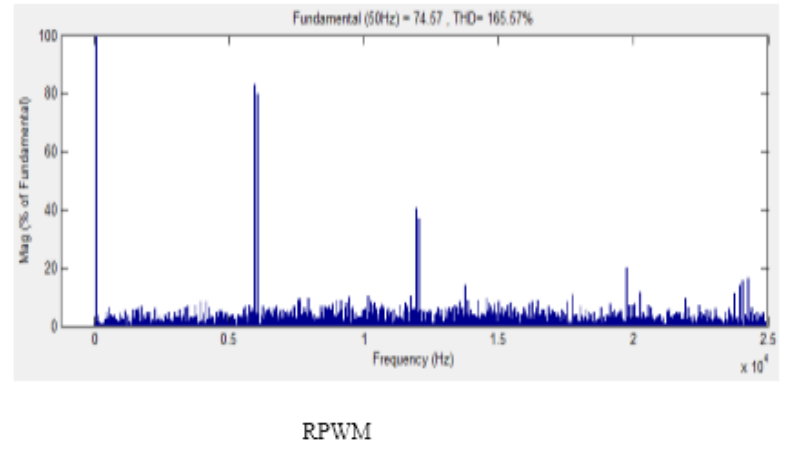

Fig 13. Spectrum of SPWM and RPWM for Modulation index $\mathrm{m}_{\mathrm{a}}=0.2$ and 0.4
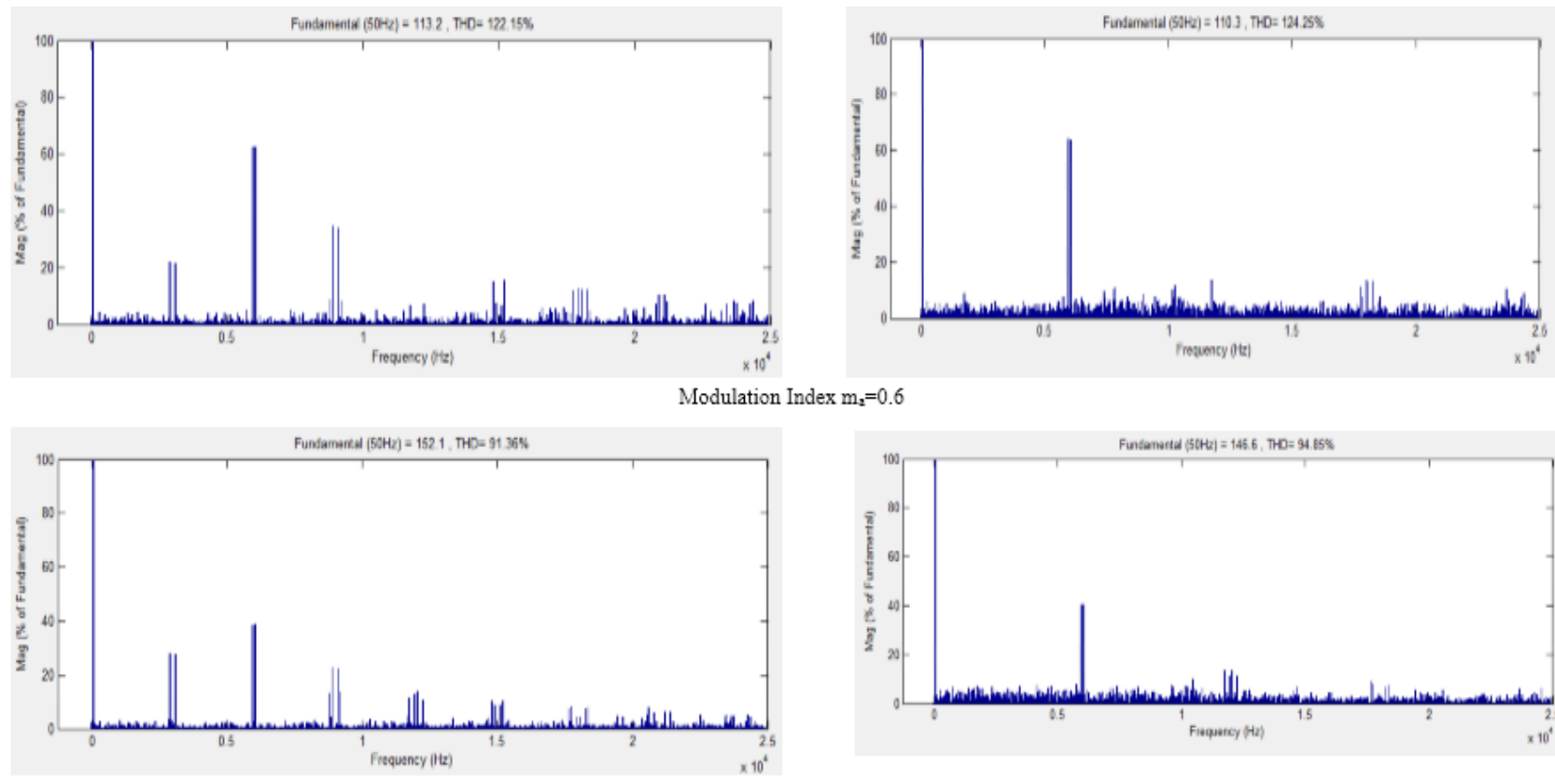

Modulation Index $m_{2}=0.6$

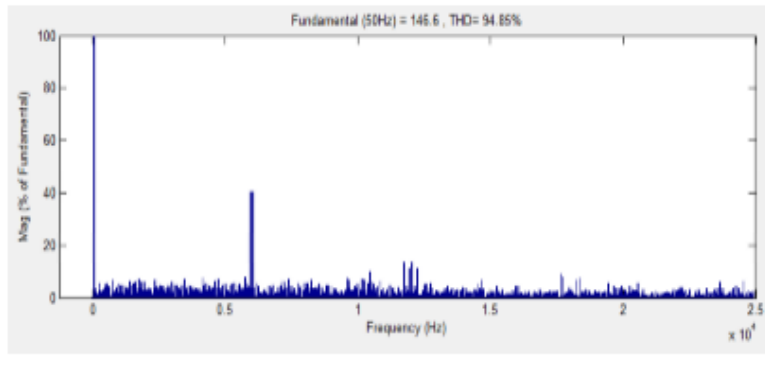

SPWM

RPWM

Modulation Index $m a=0.8$

Fig.14. Spectrum of SPWM and RPWM for Modulation index $\mathrm{m}_{\mathrm{a}}=0.2$ and 0.4 


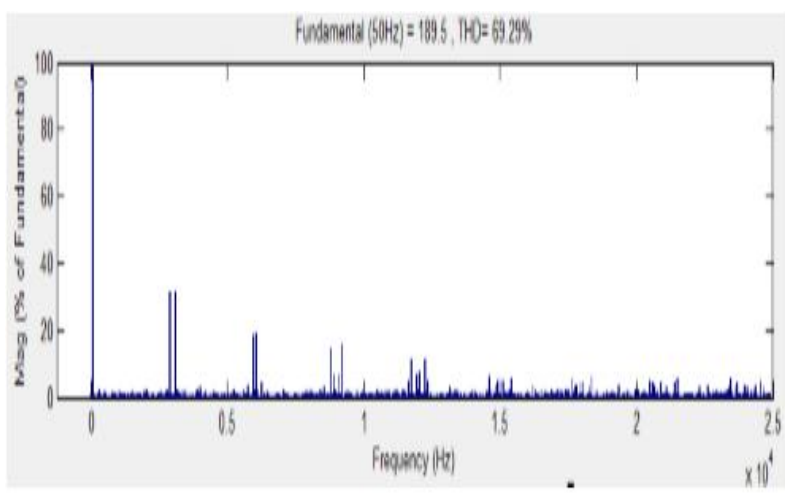

SPWM

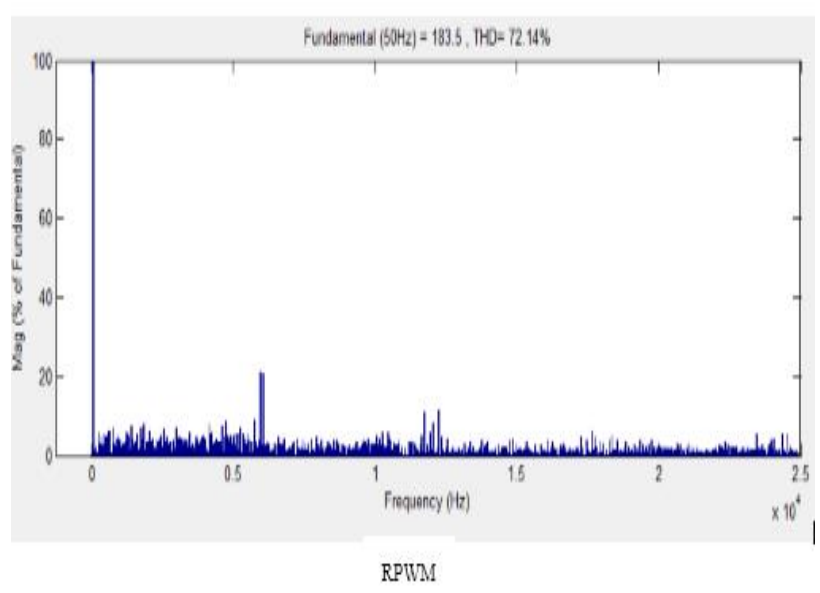

Fig 15. Spectrum of SPWM and RPWM for Modulation index $\mathrm{m}_{\mathrm{a}}=1.0$

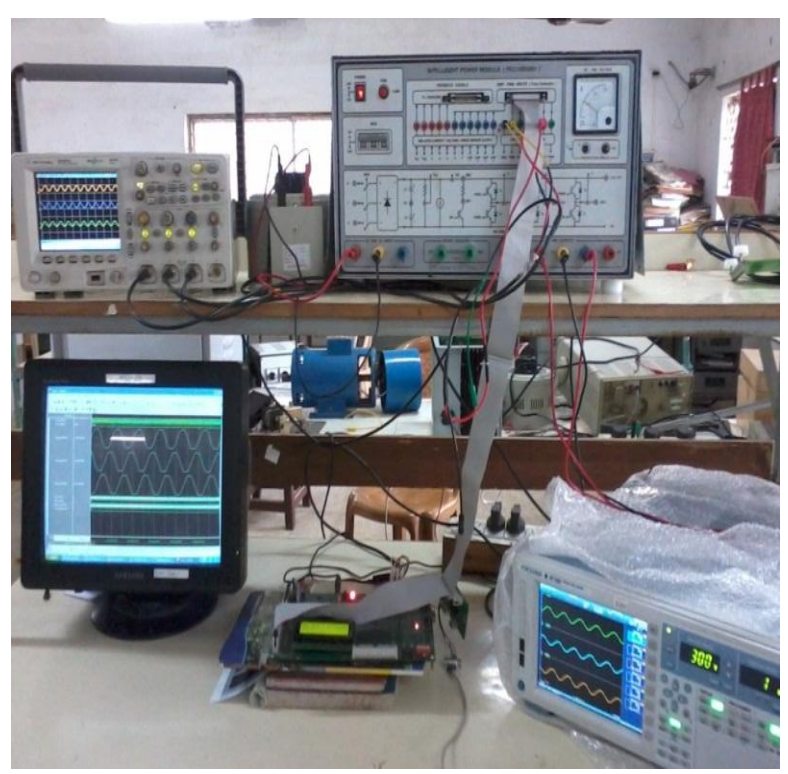

Fig 16. Experimental setup

Table 2. Performance Comparison for various modulation Indexes

\begin{tabular}{|c|c|c|c|}
\hline \multirow[b]{2}{*}{$\mathbf{m}_{\mathbf{a}}$} & $\begin{array}{c}\text { PWM } \\
\text { Techniques }\end{array}$ & \multirow{2}{*}{ SPWM } & \multirow{2}{*}{$\begin{array}{c}\text { Two } \\
\text { Triangle } \\
\text { RPWM }\end{array}$} \\
\hline & $\begin{array}{l}\text { Performance } \\
\text { Parameters }\end{array}$ & & \\
\hline \multirow{4}{*}{0.2} & Fundamental & 37.69 & 35.9 \\
\hline & $\%$ THD & 254 & 259 \\
\hline & HSF & 3.58 & 3.31 \\
\hline & $\begin{array}{c}\text { Dominating Voltage } \\
\text { Harmonics }\end{array}$ & $\begin{array}{c}58,62,119 \\
121,239,240\end{array}$ & $\begin{array}{l}119,121 \\
239,360\end{array}$ \\
\hline \multirow{4}{*}{0.4} & Fundamental & 75.56 & 73.9 \\
\hline & $\%$ THD & 162.9 & 163.9 \\
\hline & HSF & 4.78 & 4.459 \\
\hline & $\begin{array}{c}\text { Dominating voltage } \\
\text { Harmonics }\end{array}$ & $\begin{array}{c}58,62,119, \\
121,178,239 \\
\end{array}$ & $\begin{array}{l}119,121 \\
239,120 \\
\end{array}$ \\
\hline \multirow{4}{*}{0.6} & Fundamental & 112.9 & 111.9 \\
\hline & $\%$ THD & 120 & 123.1 \\
\hline & HSF & 5.379 & 4.79 \\
\hline & $\begin{array}{c}\text { Dominating voltage } \\
\text { Harmonics }\end{array}$ & $\begin{array}{c}58,62,119, \\
121,177,181\end{array}$ & $\begin{array}{l}119,121 \\
120,359\end{array}$ \\
\hline \multirow{4}{*}{0.8} & Fundamental & 150.293 & 151.1 \\
\hline & $\%$ THD & 93.61 & 92.9 \\
\hline & $\mathrm{HSF}$ & 5.489 & 4.55 \\
\hline & $\begin{array}{c}\text { Dominating voltage } \\
\text { Harmonics }\end{array}$ & $58,62,119,121$ & $\begin{array}{c}119,121,239 \\
, 120 \\
\end{array}$ \\
\hline \multirow{4}{*}{1} & Fundamental & 188.6 & 189 \\
\hline & $\%$ THD & 80.02 & 75.02 \\
\hline & HSF & 8.63 & 3.83 \\
\hline & $\begin{array}{c}\text { Dominating voltage } \\
\text { Harmonics }\end{array}$ & $58,62,119,121$ & $\begin{array}{c}119,121,77, \\
235\end{array}$ \\
\hline
\end{tabular}

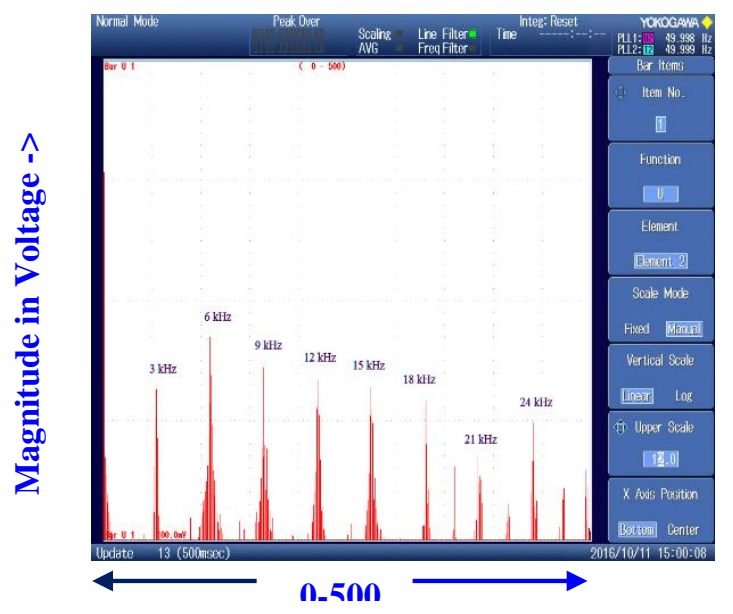

Fig 17. Harmonic spectrum of SPWM for $\mathrm{m}_{\mathrm{a}}=0.8$

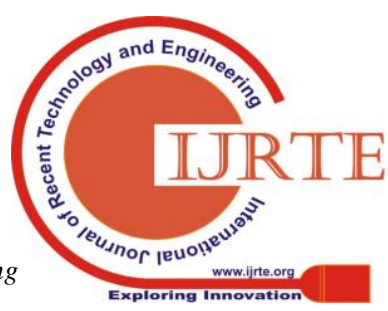




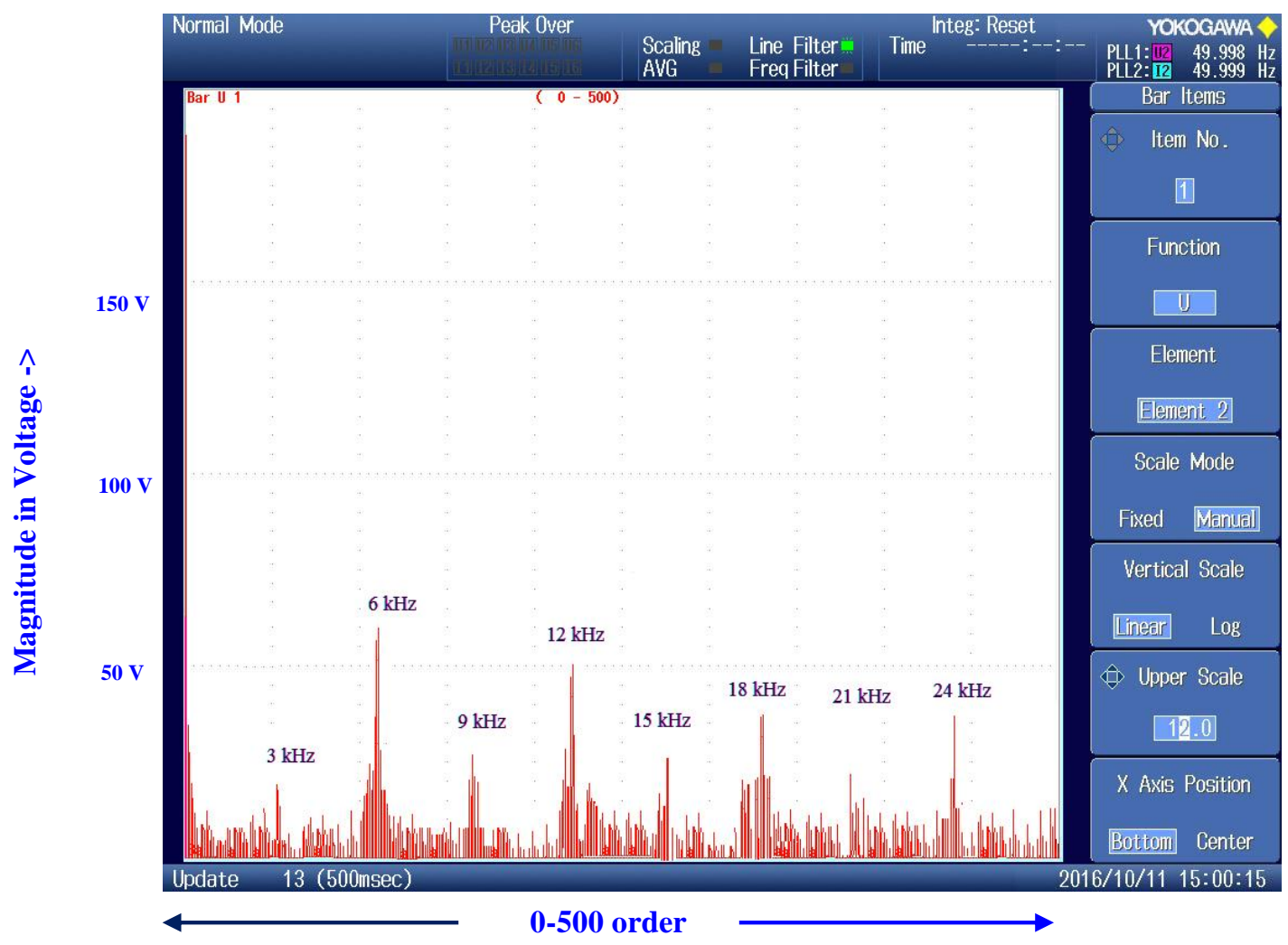

Fig 18. Harmonic spectrum of RPWM for ma=0.8

Table 5. Parameters of the system used in the

\section{hardware setup}

\begin{tabular}{|l|l|}
\hline Inverter & $3 \Phi$ Two level Inverter \\
\hline Switching Device & IGBT \\
\hline Input Voltage & 220 Volt \\
\hline Load & $3 \Phi$ Induction Motor \\
\hline Modulation Index & 0.8 \\
\hline Dead Time & $2.9 \mu \mathrm{s}$ \\
\hline Control & Open loop \\
\hline Filter & No \\
\hline
\end{tabular}

Fig 16 shows that the experimental setup for proposed control scheme of an induction motor and the various parameters of experimental setup are mentioned in the Table 3 . By using the autotransformer and a rectifier unit $220 \mathrm{~V}, \mathrm{DC}$ is fixed in the setup. The proposed RPWM signals and traditional PWM method signals are generated as per explanations given in previous sections by using FPGAboard.
The smooth transition between upper and lower switches of same leg is obtained by inserting $2.9 \mu$ seconds as an dead time of the switching of the same leg switches in inverter. The fundamental frequency of inverter voltage is $50 \mathrm{~Hz}$ for traditional PWM (SPWM) and proposed RPWM schemes. All the hardware results are analysed at different modulation index values from 0.2 to 1.0 .

In SPWM, while the frequency based $\mathrm{m}_{\mathrm{a}}$ is a numeral or rounded integer value, the modulation method is titled as synchronous PWM method. This is more appropriate for digital implementation in FPGA processor. If $(\mathrm{mf} \geq 9)$ and multiple of three, the lower order harmonics which is lesser than $\mathrm{mf}-2$ are eliminated in line voltage. In traditional SPWM, the generated harmonics in voltage waveform are centered on $\mathrm{mf}$ and multiples. i.e harmonics are presented $\mathrm{mf}$, $\mathrm{mf} \pm 2,2 \mathrm{mf} \pm 2,3 \mathrm{mf} \pm 2 \ldots . . \quad$ as shown in Fig 17. The experimental results revealed that the output harmonics are presented at the centered around the multiplies of three such as three $(1 X 3) \mathrm{kHz}, \quad \operatorname{six}(2 X 3) \mathrm{kHz}, \operatorname{nine}(3 X 3) \mathrm{kHz}$, twelve $(4 X 3) \mathrm{kHz}$, fifteen $(5 X 3) \mathrm{kHz}$ and eighteen $(6 X 3) \mathrm{kHz}$. In the harmonic spectrum each line shows the $50 \mathrm{~Hz}$. The HSF performance parameter of SPWM is giving the low value of HSF at $0.2 \mathrm{ma}$, whereas the highest value occurred at modulation index 0.8 . So, this is compassionate of band of HSF between 3.5 to 5.5 . 
Table 4. Simulation and Experimental Result comparison

\begin{tabular}{|c|c|c|c|c|c|c|}
\hline Technique & \multicolumn{5}{|c|}{ SPWM } \\
\hline & \multicolumn{3}{|c|}{ Simulation Results } & \multicolumn{3}{|c|}{ Hardware results } \\
\hline & $\begin{array}{c}\text { Output } \\
\text { Voltage }\end{array}$ & $\begin{array}{c}\text { THD } \\
\text { \% }\end{array}$ & HSF & $\begin{array}{c}\text { Output } \\
\text { Voltage }\end{array}$ & $\begin{array}{c}\text { THD } \\
\%\end{array}$ & HSF \\
\hline 0.2 & 38.04 & 253.47 & 3.57 & 36.5 & 60.67 & 3.545 \\
\hline 0.4 & 76.91 & 162.18 & 4.79 & 74.6 & 45.81 & 4.765 \\
\hline 0.6 & 113.90 & 121.54 & 5.38 & 112.5 & 30.21 & 5.355 \\
\hline 0.8 & 153.20 & 90.43 & 5.49 & 151.2 & 24.01 & 5.465 \\
\hline 1.0 & 190.19 & 69.09 & 4.49 & 186.6 & 18.66 & 4.465 \\
\hline
\end{tabular}

Table 5. Simulation and Experimental Result comparison

\begin{tabular}{|c|c|c|c|c|c|c|}
\hline Technique & \multicolumn{5}{|c|}{ RPWM } \\
\hline & \multicolumn{2}{|c|}{ Simulation Results } & \multicolumn{3}{|c|}{ Hardware results } \\
\hline $\mathbf{m}_{\mathbf{a}}$ & $\begin{array}{c}\text { Output } \\
\text { Voltage }\end{array}$ & $\begin{array}{c}\text { THD } \\
\text { \% }\end{array}$ & HSF & $\begin{array}{c}\text { Output } \\
\text { Voltage }\end{array}$ & $\begin{array}{c}\text { THD } \\
\%\end{array}$ & HSF \\
\hline 0.2 & 36 & 258 & 3.3 & 40.2 & 61 & 3.275 \\
\hline 0.4 & 74 & 164 & 4.46 & 78.3 & 47 & 4.435 \\
\hline 0.6 & 112 & 123 & 4.78 & 120.5 & 32 & 4.755 \\
\hline 0.8 & 151 & 93 & 4.56 & 163.04 & 22 & 4.535 \\
\hline 1.0 & 189 & 70.18 & 3.83 & 185 & 17.2 & 3.805 \\
\hline
\end{tabular}

In two triangle RPWM method, the harmonics are presented at $2 \mathrm{mf} \pm 2,4 \mathrm{mf} \pm 2 \ldots$ i.e the dominating harmonics are present at $6 \mathrm{kHz}$ and $12 \mathrm{kHz}$ and $18 \mathrm{kHz}$. The counterpart SPWM is having the harmonics fashioned at $3 \mathrm{kHz}$ and $9 \mathrm{kHz}$ and 15 $\mathrm{kHz}$ are suppressed in RPWM which is shown in Fig 18. In the Fundamental and THD point of view there is no much difference in the RPWM compare SPWM. But, in the HSF, is somewhat degraded compare SPWM, which makes the band between 3.27 to 4.75 as shown in Table 5 .

\section{CONCLUSION}

The digital implementation of the both traditional RPWM and proposed RPWM are described. The detailed SPWM and two triangle RPWM generation of FPGA is spoken. The spectral analysis of the above methods is carefully examined in MATLAB environment. The validity of the simulated spectral analysis is examined through experimentation. Comparisons showed an excellent equivalency between simulation and actually measured spectra. At the end of this analysis, it is to conclude that two triangle random pulse width modulation outperforms.

\section{REFERENCES}

1. Mahesh A Patel, Ankit R Patel, Dhaval R Vyas, Ketul M Patel, "Use of PWM Techniques for Power Quality Improvement", International Journal of Recent Trends in Engineering, Vol. 1, No. 4. pp. 99-102. 2009.

2. MuthukumarParamasivan, Melba Mary Paulraj, SankaragomathiBalasubramanian, "Assorted carrier-variable frequency-random PWM scheme for voltage source inverter", IET Power Electronics, vol. 10,No. 14, pp. 1993 - 2001.August 2017.

3. Seung-Wook Hyun, Seok-Jin Hong, Jung-Hyo Lee, Chun-Bok Lee, and Chung-Yuen Won, "A Method to Compensate the Distorted Space
Vectors in the Unbalanced Neutral Point Voltage of 3-level NPC PWM Inverters", Journal of Power Electronics, Vol. 16, No. 2, pp. 455-463, 2016.

4. Ki-Seon Kim, Young-Gook Jung and Young-cheol Lim, "A New Hybrid Random PWM Scheme", IEEE Transactions on Power Electronics, Vol. 24. No. 1, 192-200. 2009.

5. Nandhakumar R, Jeevananthan S, Inverted Sine Carrier Pulse Width Modulation for Fundamental Fortification in DC-AC Converters. Serbian Journal of Electrical Engineering, Vol. 4, No. 2, pp. 171-187. 2007.

6. Young-cheol Lim, Seog-Oh Wi, Jong-Nam Kim, Young-Gook Jung, “A Pseudo random Carrier Modulation Scheme". IEEE Transactions on Power Electronics, Vol. 25, No. 4, pp. 797-805. 2010

7. Boopathi R, Muthukumar P, Melba Mary P , Jeevananthan S, "Investigations on Harmonic Spreading Effects of SVPWM Switching Patterns in VSI fed AC Drives". IEEE International Conference on Advances in Engineering, Science and Management (ICAESM): pp. 651-656. 2012.

8. Valantina Stephen, L. Padma Suresh and P. Muthukumar, "Field programmable gate array based RF-THI pulse width modulation control for three phase Inverter using matlabmodelsimcosimulation", American Journal of Applied Sciences, Vol. 9, No. 11, pp. 1802-1812, 2012.

\section{AUTHOR'S PROFILE}

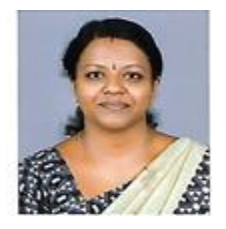

A. ${ }^{I}$ SREEJA P received her B.Tech Electrical and Electronics Engineering from T.K.M College Of Engineering , Kollam, Kerala, India on 2008 and M.E Control and Instrumentation from Anna University, Tamilnadu, india in 2011. At present she is pursuing her Doctoral degree in the depart of EEE at Noorul Islam center for higher education, Thukalay,

Tamilnadu, India.

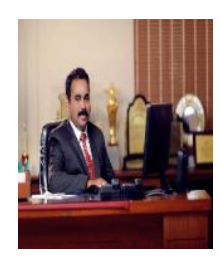

${ }^{2}$ Dr.L.Padma Suresh received his B.E. Electrical and Electronics Engineering from Noorul Islam College of Engineering on 1999 and M.E. Process Control and Instrumentation in 2000 from Annamalai University and Ph.D. Electrical Engineering in 2010 from Dr.M.G.R University and Ph.D Computer Science Engineering from M.S. University. Presently he is working as Principal of Baselios Mathews II College of Engineering, Kollam, Kerala. He has 18years of diverse experience in teaching, Life member of ISTE, and Senior IEEE Member. His Research interests in Artificial Intelligence, Control Systems, Power Electronics and Image Processing.

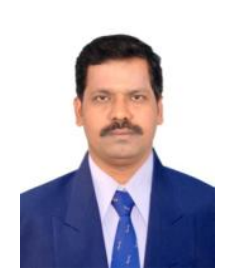

${ }^{3}$ Dr.P. Muthukumar received his B.E. Electrical and Electronics Engineering from Noorul Islam College of Engineering on 1999 and M.E. Power Electronics and Drives in 2005 from Anna University and Ph.D.

Electrical Engineering in 2017 from Anna University, Chennai-India. Presently he is working as an Associate Professor in EEE Dept. of PVP Siddhartha Institute of Technology, Vijayawada-India. He has 16 years of diverse experience in teaching and corporate industry and a member of IEEE and ISRD. His Research interests in Renewable Energy Sources, Power Electronics and Drives and VLSI. 